\title{
A collaborative endeavour between mathematics and science educators: focus on the use of percent in chemistry
}

\author{
Ajay Ramful ${ }^{1}$, Danny Bedgood ${ }^{2,}$ and Thomas Lowrie ${ }^{3}$ \\ ${ }^{1}$ Faculty of Education, Science, Technology and Mathematics, University of Canberra, ACT, Australia \\ 2,*Faculty of Agricultural \& Wine Sciences, Charles Sturt University, Wagga Wagga, Australia \\ ${ }^{3}$ Faculty of Education, Science, Technology and Mathematics, University of Canberra, ACT, Australia \\ For correspondence: ajay.ramful@canberra.edu.au
}

\begin{abstract}
This paper is the outcome of a collaborative endeavour between mathematics and science educators where the insight from each field mutually informed one another. Specifically, building on the knowledge base from mathematics education research, this study analyses the ways in which percent is interpreted by first year university students in general chemistry. The content analysis of the chemistry problems reveals six categories of situations where percent is distinctly used. Within each category, we unfold the mathematical structure of the chemistry problems to feature the inherent complexity in setting the functional relationship among quantities. Our analysis also highlights how percent is used as an intensive quantity involving an implicit referent that conceals its interpretation. The strategies used by the students included the unitary analysis method, the equation method and the proportion method. Furthermore, percent was commonly interpreted as a fraction, ratio and operator. Although inadequate conceptual knowledge of chemistry explained some of the errors observed in the percent problems, the procedural meaning attached to percent in terms of its operator interpretation tend to be equally influential. Importantly, our study highlights how the knowledge base from mathematics and chemistry education can productively be used to further our understanding of the mathematical knowledge for learning chemsitry.
\end{abstract}

Keywords: percent, chemistry, mathematics education, science education

\section{Introduction}

The importance of mathematical proficiency in solving chemistry problems.Proficiency in mathematics is central for the study of chemistry (Scott, 2012). As a body of knowledge, chemistry relies extensively on mathematical ideas ranging from numbers to calculus. Mathematical concepts such as decimals, percent, ratio, proportion, rate, measurement, logarithms, integration and differentiation are used to describe chemistry concepts. Further, mathematical representations in the form of numbers, algebraic formulae and graphs are the means through which chemical principles are ideated and mediated. Mathematical concepts are essential for the description and interpretation of scientific phenomena as characterized by quantitative analysis in chemistry. Consequently, lack of proficiency and disposition towards mathematics can be a barrier in the learning of chemistry and prevents students from pursuing science-related studies. Indeed, correlation studies have shown that SAT scores in mathematics are a good indicator of performance in college chemistry (Spencer, 1996). Research has shown that lack of understanding of mathematical concepts constrains students from understanding chemistry ideas conceptually. For instance, DePierro et al. (2008) and Park and Choi (2012) have shown that difficulties in manipulating logarithms impact on students' understanding of $\mathrm{pH}$ values. In their study related to the application of algebraic and graphical skills in chemistry, Potgieter et al. (2008) found that the absence of adequate conceptual understanding in mathematics was a more significant determinant of students' success in chemistry than the application of those skills in chemistry.

Generally, the requisite foundational mathematical skills for the study of chemistry are known; however, what have not been made fully explicit are the specificity of the mathematical knowledge 
and skills that are necessary for the solution of chemistry problems in the different domains of the subject. One way to tease out such mathematical knowledge and skills is to analyse the structure of problems in chemistry on a domain-by-domain basis. Specifically, this study conceptually analyses the mathematical dimension of chemistry problems in one particular domain, namely percent. It scrutinizes the ways in which percent is used in describing chemistry concepts with regard to the inherent level of complexity using the knowledge base from mathematics education. It focuses explicitly and extensively on the mathematical dimension of chemistry problems involving percent. Subsequently, in the empirical phase, students' responses to percent problems are analysed to identify the meaning that they attributed to percent as they solved the systematically devised problems.

Functional use of percent in chemistry: The science educators' lens. Percent is a widely used concept in chemistry to functionally describe quantities. For instance, forensic chemists determine the nature of unknown substances by comparing their percentage composition to that of known ones such as sugar or salt (Brown et al., 2012). The price of coal is determined by the percentage of carbon that it contains. Similarly, percent is used to measure the degree to which atoms are packed in a crystal where the indicator packing efficiency denotes the fraction (or percent) of space in a crystal that is actually occupied by atoms (Brown et al., 2012). Chemists find it logically appealing to define percentage by mass of a particular element. For instance, when a new compound is synthesized, one of the analytical methods used to identify it or confirm its identity, is elemental analysis (Ebbing and Gammon, 2005). This quantitative method uses percentage composition as one of the underlying techniques. Sometimes, the nature of the chemical reaction motivates the use of the percent concept. For instance, the definition of the concept of percentage yield becomes important as chemical reactions may not occur completely, forming less product than can be predicted. Thus, in these types of reactions, it is practically significant to define a concept that can capture the amount that is actually produced as compared to the amount that is theoretically expected. This is precisely what percentage yield does in computing the fraction 'actual amount/theoretical amount' as a percentage. The intricate ways in which percent are used in chemistry is discussed in the content analysis section of the paper.

What is known about percent from the mathematics education literature?: The mathematics educators' lens.Generally, percentages are used in three ways in social contexts: to represent fractions, to compare numbers, and to show percentage increase or decrease (Siemon et al., 2011). As for the school mathematics curricula, traditionally, the mathematical structure of percentage problems has been described in terms of three categories (Dole et al., 1997, p. 148): (a) Case I: Find a part or percent of a number (e.g., $25 \%$ of 20); (b) Case II: Finding a part or percent that one number is of another (e.g., p \% of 20 is 5); and (c) Case III: Finding a number when a certain part or percent of that number is known ( $25 \%$ of $\mathrm{p}$ is 5). The method of solving percent problems according to the three categorization is termed the Case Method by Parker and Leinhardt (1995).In their extensive review of research, Parker and Leinhardt (1995) enumerate the ways in which percentages can be interpreted (e.g. as a fraction, ratio or proportion) and map out the strategies used and obstacles that students encounter in making sense of this mathematical domain. This knowledge base is used as the main source of information to conduct the first phase of the study in terms of the theoretical analysis of chemistry problems involving percent. Error analysis studies have both quantitatively and qualitatively illustrated the different types of misunderstandings with the concept of percent (Lembke, 1991; Parker and Leinhardt, 1995; Risacher, 1992). For instance, students tend to ignore the meaning of the percent sign, dropping and inserting the percent sign at will, making no distinction between $1 / 2$ and $1 / 2 \%$. Further, the relationship between percent and decimals is problematic. For example, students tend to replace the percent sign to the right of the numeral by a decimal to the left of the numeral (e.g., 0.7 as $7 \%$ ). Students also tend to rely much more on rules rather than on the meaning of percent. For instance, the answer 2 is given to " $4=\ldots \%$ of 8 ". Moreover, some students with a strong partwhole conception of percent experience difficulties in interpreting percent increase and percent decrease. The subtle nature of percent is partly due to its multiplicative characteristic. For example, if the price of a commodity increases from $\$ 30$ to $\$ 45$, then the additive change is $\$ 15$ but multiplicatively, the price has increased by $(15 / 30) \times 100 \%=50 \%$. With regard to the strategies employed to solve percent problems, Parker and Leinhardt (1995) surveyed five procedures, namely 
the Case Method, the Equation Method, the Unitary Analysis Method, the Formula Method, and the Method of Proportion. The Case Method was explained earlier. In the Equation Method, the percent problem is written as follows: factor $\times$ factor $=$ product. For example, we translate the question " 18 is $15 \%$ of what" to $18=0.15 \times \mathrm{x}$ and we solve for $\mathrm{x}$ to obtain 120. In the Unitary Analysis Method, we find the amount corresponding to $1 \%$ and and then construct $100 \%$. In the foregoing example, if $15 \%$ corresponds to 18 , then $1 \%$ corresponds to $18 / 15$ and $100 \%$ amounts to $(18 / 15) \times 100=120$. The Formula Method is quite similar to the Equation Method, except that it uses the equation, percentage $=$ base $\times$ rate rather than using $x$ to represent the unknown quantity. The Proportion Method requires that the percent is expressed as a fraction and set equal to a second fraction as follows: $15 / 100=18 / x$ which yields $x=120$ on cross multiplication. We give further illustrations of some of these methods in chemistry problems in the data analysis section.

Meanings of percent. The mathematics education literature has highlighted the multifaceted meanings of percent. In this section, we discuss these subtle differences using chemistry problems where percent is customarily used. Although represented by the same notation, a percent may be interpreted in different ways depending on the context of the situation. We now present the five meanings of percent from Parker and Leinhardt (1995).

Percent as an intensive quantity.Parker and Leinhardt (1995) also drew our attention to analyze a percent from the perspective of a quantity. They argued that "mathematically, the appearance of the percent language flags the entry into an intensive world of comparison" (p. 438). As explicitly exemplified by Singer et al. (1997, p.116): "Extensives quantify how much of a substance or how many of a class of objects are present. Extensive quantities behave additively; that is, they can be combined and partitioned in ways that match the combination and partitioning of amounts of physical material in the world ... Intensives, by contrast, are relational quantities that describe how two different extensives are related to one another. Rates, such as 5 apples per box, $\$ 3$ per hour, or 30 miles per gallon, are all intensive quantities." Examples of extensives include length, mass, volume and so forth. A minor clarification is in order regarding the use of the terms 'extensive' and 'intensive' quantities/properties in mathematics and science education. While mathematics educators refer to extensive and intensive quantities, chemists tend to refer to extensive and intensive properties of matter. By extensive properties of matter, chemists mean attributes such as length, volume and mass which depend on the amount of matter present. They refer to intensive properties of matter to attributes such as temperature, boiling point and density which do not depend on the amount of matter.

Percent as a number. A percent can be interpreted as a number in the sense that it can be ordered linearly to allow comparisons with respect to the same referent. For example, three different ores, having $10 \%, 15 \%$ and $20 \%$ of iron respectively can be arranged in increasing amount of iron (the referent). One of the advantages of using percent is that it allows relative (rather than absolute) comparisons to be made. For example, in the comparison of the percentage composition of nitrogen in ammonium nitrate $\left(\mathrm{NH}_{4} \mathrm{NO}_{3}\right)$, ammonium sulfate $\left(\mathrm{NH}_{4}\right)_{2} \mathrm{SO}_{4}$ and urea $\left(\mathrm{NH}_{2}\right)_{2} \mathrm{CO}$, although each of the compounds has two atoms of nitrogen per formula unit, their relative content of nitrogen by mass is different. Percent is regarded as a number not only because it can be ordered but equally because it can be added, depending on the particular situation. For example, when the percentage composition of each element is added in a compound, it yields $100 \%$. However, addition of percents can only be accomplished if they refer to same base. For example, if a solution containing $10 \%$ sodium chloride is mixed with another solution containing $15 \%$ sodium chloride, then the two percents cannot be added directly as percents are primarily used as an intensive quantity in chemistry. The percent symbol is also interpreted as hundredths, per hundred or out of 100 . This interpretation of percent is particularly useful in chemistry. For example, a solution containing $5 \% \mathrm{HCl}$ makes sense when we think of 5 gram of $\mathrm{HCl}$ per $100 \mathrm{ml}$ of water; here the $5 \%$ would have units of weight/volume - 5\% w/v. Similarly, consider a compound with the following composition by mass - Carbon: $66.7 \%$; Hydrogen: $11.1 \%$; and Oxygen: $22.2 \%$. Then if $100 \%$ is interpreted as $100 \mathrm{~g}$, the compound can be regarded as having $66.7 \mathrm{~g}, 11.1 \mathrm{~g}$ and $22.2 \mathrm{~g}$ of Carbon, Hydrogen and Oxygen respectively. A percent is often interpreted in terms of a decimal (a number), e.g., $5 \%$ is the same as 0.05 . Thinking 
interchangeably with percents (e.g., $5 \%)$ and decimals $(0.05 \mathrm{~g})$ offers much affordance in making sense about chemical quantities.

Percent as a fraction and a ratio. A percent is essentially a statement of comparison involving a fraction or a ratio. For instance, $25 \%$ can be interpreted as the fraction $25 / 100$ or $1 / 4$ and as the ratio $25: 100$ or 1:4. As a fraction, it involves a part-whole comparison (a subset is compared to the whole set): how many $25 \mathrm{~s}$ in 100. As a ratio, two disjoint sets are compared - a set of 25 and a set of 100 . Let us consider the following example (involving percentage abundance) in terms of a ratio and a fraction. Silver has two naturally occurring isotopes, $107 \mathrm{Ag}$ and 109Ag which are present in the ratio $51.84 \%$ and $48.16 \%$ respectively. On the other hand, the fraction interpretation becomes more appropriate when we are dealing with the individual isotopes: 51.84 'parts' out of the 100 'parts' involve 107Ag. The fraction and ratio interpretation depends on the context of the problem. For instance, in interpreting percent ionization which is defined as (concentration ionized)/(original concentration) $\times$ $100 \%$ (Brown et al. 2012), the fraction meaning appears to be more useful.

Percent as a functional operator. The functional operator interpretation of percent essentially refers to its use as a multiplicative operator, i.e. apply a given percent on a quantity. Risacher (1992, p.41) describes the operator meaning of percent as "an action to be performed on a quantity." For instance, if the tax rate is $12 \%$, how much does one pay on a monthly salary of $\$ 7000$ ? This situation invokes a multiplying action, i.e., $12 \%$ of $\$ 7000$. Here, percent is used to establish a functional relationship between an original amount (input) and a final amount (output) and does not necessarily take into account the element of comparison as in the fraction or ratio meaning. Percent is used to create a new number by operating on a given base. The operator conception may account for students' difficulty with percent as highlighted by Parker and Leinhardt (1995, p. 444): "Given a percent, many students' first instinct is to multiply, whether or not the base (input) is given."

Percent as a statistic. A percent is interpreted as a descriptive statistic when it is used to report the relative size of one quantity in relation to another. For instance, rather than reporting that the expenses of the State on environmental protection increased by the absolute amount $\$ 20$ million, the relational language of percent might be used to say there was a $12 \%$ increase in spending on environmental protection. The referent quantity used to compute the percent statistic may or may not be provided. We did not find explicit applications of the statistic meaning of percent in chemistry.

The subtle and demanding nature of percent as revealed by research in mathematics education and its widespread use in chemistry, make it educationally significant to ask the following two research questions: (1) In what ways is percent used in the description of chemistry concepts with regard to its computational aspect? (2) How do students interpret percent in different types of chemistry problems? The succeeding sections of the paper are organized as follows. Firstly, the methods used to answer the two research questions are outlined. Then, the content analysis of percent in chemistry is described. In the ensuing section, empirical data are presented to illustrate the strategies used and interpretation attributed to percent by first-year university students. Finally, the discussion and conclusion are presented.

\section{Methods}

Methodologically, our study consisted of two phases. The first phase involved the content analysis of percent problems from first-year general chemistry course books from recommended textbook series (e.g., Brown et al., 2012; Chang, 2007; Ebbing and Gammon, 2005; Silberberg, 2009). We also examined percent problems from the Cambridge International Examination Board (Chua, 2000). By content analysis we mean the appraisal of chemistry contexts where percent is used in first year university general chemistry courses and importantly the examination of the mathematical structure of the underlying problems. We were more interested in scrutinizing the ways in which percent was used rather than quantitatively weighing the extent of its use. The value of conducting such a theoretical analysis has been highlighted by Nesher (1988, p.38): "the significance of any theoretical analysis is that it enables us to hypothesize the major parameters that have explanatory power for the 
observed phenomena." We categorized the chemistry problems from the textbooks and examination papers by analyzing the distinct ways in which percent is used. This analysis allowed us to identify 6 categories of percent problems (Table 1).

Table 1. Uses of percent in quantitative problems in chemistry

\begin{tabular}{clc}
\hline Type & \multicolumn{1}{c}{ Nature of question } & Question \\
\hline Type 1 & Direct interpretation problem (e.g. reading \% from charts) & $1.1,1.2,1.3,1.4$ \\
Type 2 & $\begin{array}{l}\text { Given a compound, find mass percent or percentage } \\
\text { composition }\end{array}$ & 2.1 \\
Type 3 & $\begin{array}{l}\text { Relationship between percentage composition, molecular } \\
\text { mass and molecular formula }\end{array}$ & 3.1 .3 .2 \\
Type 4 & $\begin{array}{l}\text { Percentage yield } \\
\text { Type 5 }\end{array}$ & $\begin{array}{c}\text { Percentage purity } \\
\text { Type 6 }\end{array}$ \\
\hline
\end{tabular}

In the second empirical phase of the study, sample problems from the 6 types of situations were used to devise an instrument (see Appendix) for identifying the strategies used by the students and the meaning that they attributed to percent. The last column of Table 1 indicates the question number in the instrument used to collect data. The justifications for the selection of the tasks in the instrument are intertwined in the data analysis section.

Participants and data collection. Data were collected from nine first year students (average age 18.5 years) from a rural Australian university enrolled in different science-related areas (Veterinary science, Animal science and Equine science) in March 2014. The background information provided by the students showed that they had scored $60 \%$ or higher in their mathematics and chemistry examinations (Higher School Certificate) at the end of secondary schooling (Table 2). All the students had studied approximately one semester of general chemistry when they took part in the study. The students were given one and one quarter hours to complete the percent instrument in the chemistry laboratory. They were allowed to use their calculator. Most of participants took one hour to work out the problems. As we were personally involved in the administration of the questionnaire, we could observe that they dedicatedly worked out the problems. A movie voucher was given as a motivation to participate in the study.

Table 2. Profile of participants

\begin{tabular}{ccc}
\hline $\begin{array}{c}\text { Student } \\
\text { code }\end{array}$ & $\begin{array}{c}\text { Mathematics } \\
\text { score }\end{array}$ & $\begin{array}{c}\text { Chemistry } \\
\text { score }\end{array}$ \\
\hline S1 & 80 & 65 \\
S2 & 64 & 85 \\
S3 & 87 & 91 \\
S4 & Not given & Not given \\
S5 & 89 & 87 \\
S6 & 65 & 80 \\
S7 & 86 & 88 \\
S8 & 83 & 84 \\
S9 & 80 & 80 \\
\hline
\end{tabular}

\section{Results}

We present the results in two sections. In the first section, we describe our findings from the content analysis about the six categories of percent situations in chemistry. In the second section, we provide empirical data from students' responses to each category of percent situations.Based on our discipline knowledge, we saw different things in the data as mathematics and science educators. While the mathematics educators looked at the data with the nuances in the ways in which percent was being articulated by the students, the science educator was more inclined to see the chemistry dimension in the problems posed to the students. 
Content analysis of percent in chemistry. As mentioned earlier, the aim of the content analysis from the textbooks was meant to survey the different ways in which percent is used. Within each type of percent situations, structural and numeric variations can be effected to create different problems as will be highlighted below. We illustrate each type of situation in an attempt to show the distinctive ways in which percent is used and the mathematical structure of the underlying problems.

Type 1. Type 1 situations involve the use of percent as a number or as a fraction in terms of a partwhole comparison or as a ratio in terms of part-part comparison. In question 1.1, part (i) (see Appendix) uses percent as a number in terms of comparison of magnitude, i.e., comparing the relative content of nitrogen in the four fertilizers as a percentage. Part (ii) refers to the use of percent as an operator; in other words applying a percent on a given quantity, i.e., taking $10 \%$ of 500 grams. Conversely, it is equally important to work backward from a given percent to find the quantity corresponding to $100 \%$. Question 1.4 requires the construction of $100 \%$ from $21 \%$. While Type 1 problems can be solved with basic knowledge of chemistry, the other five types of situations require more background knowledge.

Type 2. Type 2 situations involve percentage by mass or percentage composition which refers to the amount (expressed in percent) each element in a compound or molecule contributes to the molecular mass. The definition of percent composition essentially uses the fraction interpretation of percent. For instance, in question 2.1, the three fertilizers, ammonium nitrate $\left(\mathrm{NH}_{4} \mathrm{NO}_{3}\right)$, ammonium sulfate $(\mathrm{NH} 4)_{2} \mathrm{SO}_{4}$, and urea $\left(\mathrm{NH}_{2}\right)_{2} \mathrm{CO}$ have the same number of nitrogen atoms but the percentage composition of nitrogen is different as the molecular mass of the three compounds are different. The percentage composition of nitrogen in the three compounds is $35 \%, 21.2 \%$ and $46.7 \%$ respectively.Mass percent and percentage composition essentially uses percent in the same way except that the two concepts are generally used for different applications. Mass percent is typically used as a concentration (e.g., sea salt is $3.5 \%$ by mass of salt) or in terms of purity (e.g., an ore is $15 \%$ iron). Percentage composition is used in relation to molecular formula (e.g., the percent composition of carbon in carbon dioxide is $27.3 \%$ ).

Type 3. One of the important uses of percent in chemistry is the functional relationship it establishes between molecular mass and empirical or molecular formula. Consider question 3.1, where the compound contains two elements namely sulphur and oxygen in the mass ratio $50 \%: 50 \%$. The atomic masses of sulphur and oxygen are $32 \mathrm{~g}$ and $16 \mathrm{~g}$ per mole. Given the explicit multiplicative relationship between the two atomic masses, it can be deduced that one atom of sulphur combines with two atoms of oxygen so that the ratio of masses is $32: 16 \times 2$, i.e., $1: 1$ according to the stated ratio, 50\%:50\%. However, the relationship between the elements in a compound may not be obvious if the mass percents are not multiples of each other. For instance, if a hydrocarbon contains $85.7 \%$ carbon and $14.3 \%$ hydrogen by mass, what is the molecular formula? If we assume that $x$ atoms of carbon (atomic mass $=12 \mathrm{~g} / \mathrm{mole}$ ) combines with $y$ atoms of hydrogen (atomic mass $=1 \mathrm{~g} / \mathrm{mole}$ ), then the molecular formula can be written as $\mathrm{C} x \mathrm{H} y$ and the corresponding molecular mass is (12) $x+(1) y$. Thus, the following ratio can be set up: $(12 x /(12 x+y)) \times 100 \% \quad((1 \times y) /(12 x+y)) \times 100 \%=85.7 \% \quad 14.3 \%$ or $x y=(85.7 / 12)(14.3 / 1)$ or $1: 2$.

In other words, the atomic ratio is produced by dividing the percentage composition of the elements by their respective atomic masses. The relationship between the triplet of quantities (atomic ratio, percentage composition and atomic masses) can be used to formulate different types of problems (see questions 3.1 and 3.2). Such variations arise naturally in the chemist's laboratory. Often chemists are not aware of the identity of chemicals they are analysing. They can determine the masses of the elements experimentally which in turn can be used to find the percentage composition. Then they can work backward to find the molecular formula of the unknown compound. We provide an example of this category of problems in question 3.2.

Type 4. Another commonly used concept is percentage yield which measures the efficiency of a reaction by computing the fraction 'actual yield/theoretical yield' as a percentage. Often limiting reagents determine the extent to which a particular product is formed. Question 4.1 involves the calculation of percentage yield in the manufacture of propan-2-ol from propene. The chemical 
equation suggests that one mole of propene yields one mole of propan-2-ol or in terms of atomic masses, $42 \mathrm{~g}$ of propene gives $60 \mathrm{~g}$ of propan-2-ol. Proportionally, $200 \mathrm{~kg}$ of propene will theoretically yield $(60 / 42) \times 200=286 \mathrm{~kg}$ of propan-2-ol. Thus, the percentage yield or efficiency of the reaction is $(150 / 286) \times 100 \%=52.4 \%$. In contrast, in question 4.2 , the percentage yield is given and the mass of the reagent that reacted has to be found.

Type 5. Another chemistry concept that is defined on the basis of percent is percentage purity. It is computed from the fraction 'mass of pure product/mass of impure products' expressed as a percentage. We use question 5.1 to illustrate the concept of percentage purity where it is important to use the mole ratio given in the chemical equation as in the case of percentage yield. In this example, the mass of $\mathrm{BaSO}_{4}$ (and equivalently the number of moles) produced depends on the mass of $\mathrm{Na}_{2} \mathrm{SO}_{4}$ used. Since 23.3/233=0.1 moles of $\mathrm{BaSO}_{4}$ was produced, this implies that 0.1 moles or $0.1 \times 142=14.2 \mathrm{~g}$ of $\mathrm{Na}_{2} \mathrm{SO}_{4}$ was used. Thus, the percentage purity of the sample is $(14.2 / 15.0) \times 100 \%=95 \%$.

Type 6. We created a specific category for the definition of concentration in terms of percent given its significance and mathematical complexity.The concentration of a solution can be expressed in terms of percent as 'percent by mass', 'percent by volume' or 'mass/volume percent', depending on whether the solute is a solid or liquid. For example, a $10 \%$ by mass aqueous solution of sodium chloride contains $10 \mathrm{~g}$ of sodium chloride per $100 \mathrm{~g}$ solution. In other words, percent by mass = (mass of solute/mass of solution) $\times 100 \%$. If the solute is a liquid, then concentration is defined as percent by volume $=($ volume of solute $/$ volume of solution $) \times 100 \%$. For example, a solution containing $10 \%$ alcohol has $10 \mathrm{~mL}$ of alcohol for every $100 \mathrm{~mL}$ of solution. Mass/volume percent is defined as (mass of solute (in grams)/volume of solution (in $\mathrm{mL}$ )) $\times 100 \%$. For example, if a solution contains $5 \mathrm{~g}$ of solute per $100 \mathrm{~mL}$ of solution, then the mass/volume percent $=(5 \mathrm{~g} / 100 \mathrm{~mL}) \times 100 \%=5 \%$.

Each of the above definitions of concentration requires the manipulation of a ratio between two quantities, namely mass or volume of solute and solution. In using percent, chemists tend to relegate or suppress its referent with the consequence that only the informed user of the concept can deduce the referent. For example, in a solution containing $20 \% \mathrm{HCl}$, the referent of the $20 \%$ is not directly visible. Here, percent tend to be used as a standardized intensive quantity. Such a solution contains $20 \mathrm{~g}$ of $\mathrm{HCl}$ per $100 \mathrm{~mL}$ of water. The concentration of the solution $(\mathrm{HCl})$ is defined as (mass/volume) $\times 100 \%,(20 \mathrm{~g} / 100 \mathrm{~mL}) \times 100 \%=20 \%$. The intensive quantity 'mass/volume' is standardized on a base of $100 \%$ and the volume is purposefully chosen to be $100 \mathrm{~mL}$ as a standard unit of measure. Quinn \& Mills (1998) argued that describing concentration in terms of the symbol '\%' constitute a misuse since concentration is not a dimensionless quantity as it involves two different quantities, e.g., mass and volume.

We include a brief note on the concept of mole given its relevance to the interpretation of the students' work presented in the empirical section of the paper. The mole is a particular unit of measurement quantifying the number of particles present in a compound. The number of moles of a compound is obtained by dividing thegiven mass by its relative molecular mass. The unit mole allows chemists to work at the microscopic level using macroscopically observable quantities such as mass and volume.For example, $50 \mathrm{~g}$ of glucose $\left(\mathrm{C}_{6} \mathrm{H}_{12} \mathrm{O}_{6}\right)$ contains $50 / 180=0.278$ moles, where 180 is the molecular mass of glucose. In the case of gases, one mole occupies $24000 \mathrm{~cm}^{3}$ at room temperature and pressure. The unit 'mole' has been reported to be a challenging concept for students, mainlybecause of its abstract nature (Gorin, 1994).

A snapshot of students' interpretation of percent. In this section, we illustrate the ways in which percent was interpreted by the sample of first year university students in solving the specifically devised problems. We analyzed the data paying particular attention to the meaning that they attributed to percent and the strategies that they used, in accord with the second research question. Given the small sample of respondents, we were more inclined to give responses illustrative of the constructs described earlier (such as percent a fraction, ratio, operator, intensive quantity) rather than giving patterns of responses which a quantitative study may address in the future. We present the findings as per the 6 types of problem situations in Table 1 . We justify the reasons for including the particular question in the instrument in the presentation of the results in each category of tasks. 
Type 1: Percent interpretation problems. To get a sense of the students' general understanding of percent, we asked them to interpret a chart involving percent in question 1.1. Similarly, we asked them to solve the traditional percent problems in question 1.2 which are numerical in nature without a chemistry context. To understand how they interpreted percent in a simple chemistry context, we asked them to explain the meaning of the statement "a hydrocarbon contains 75\% by mass of carbon" in question 1.3. We could observe the different interpretations (as a fraction, as a ratio and as a partwhole structure) that they gave to percent in their responses: "If it contains $75 \%$ this means it's $3 / 4$ carbon"; "a substance with a ratio of carbon to hydrogen being 3:1 by mass" and "75 $\mathrm{g}$ of the $100 \mathrm{~g}$ of the hydrocarbon is carbon" as well as qualitative interpretation such as "the molecule has a high content of carbon".

In question 1.4, the participants were required to construct $100 \%$ from a given percent $(21 \%)$. The common strategy was to use the Unitary Analysis Method (explained earlier) to find the amount corresponding to $1 \%$ and then to determine 100\% (see Figure1(a) for a sample answer). Another strategy was to translate the problem statement into a formulaic representation as shown in Figure 1(b). This strategy actually corresponds to the Proportion Method explained earlier.An exemplification of the Equation method is given in Figure 1(c).

$$
\begin{aligned}
6000 \mathrm{~cm}^{3} & =\frac{21}{100} \\
\therefore 6000 \div 21 & =1 \% \\
& =285.7143 \\
100 \% & =1 \% \times 100 \\
& =285.7143 \times 100 \\
& =28571.43 \mathrm{~cm}^{3}
\end{aligned}
$$

(a)

$$
\begin{aligned}
& 6000 \mathrm{~cm} \cdot=21 \% \\
& \text { fircone: } \\
& \therefore 21 \%=\frac{6000 \mathrm{cor}^{3}}{\text { Arvoleme }} \times 100 \\
& \frac{21}{100}=\frac{6000 \mathrm{~cm}}{A .0 \mathrm{mlen}} \\
& \text { Airvolare: }-6000 \cdot \frac{100}{21} \\
& =28571 \cdot 42857 \cos 3 \\
& \text { A.rvolume }=28571 \mathrm{~cm}^{3}
\end{aligned}
$$

(b)

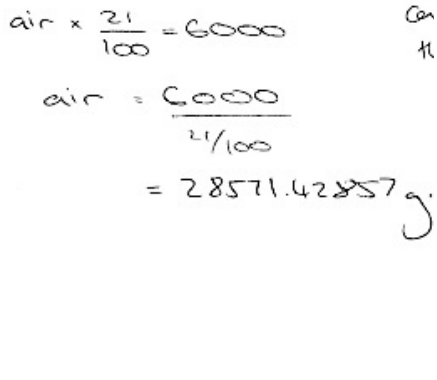

(c)

Figure 1. (a) Unitary analysis method, (b) Proportion method, and (c) Equation method

Student S9 made the following incorrect calculation (Figure 2) in question 1.4 by essentially computing $121 \%(100 \%+21 \%)$ of 6000 rather than finding the number which when multiplied by $21 \%$ gives 6000. We suspect that the possible source of error for this approach emanates from the misinterpretation of the problem context or inadequate conceptual understanding of percent, intuitively interpreted as an operator, i.e., seen as involving multiplication.

$$
\begin{aligned}
6000 \mathrm{~cm}^{3} & \\
\text { Air }=21 \% \text { ? } & \\
\therefore \text { volume of air } & =6000+21 \% \times 6000 \\
& =6000+0.21 \times 6000 \\
& =7260 \mathrm{~cm}^{3}
\end{aligned}
$$

Figure2. Incorrect construction of $100 \%$

Type 2: Mass percent or percentage composition.In question 2.1, the students used percent by mass to determine that urea $\left(\mathrm{NH}_{2}\right)_{2} \mathrm{CO}$ had the largest amount of nitrogen compared to ammonium nitrate $\left(\mathrm{NH}_{4} \mathrm{NO}_{3}\right)$ and ammonium sulfate $\left(\mathrm{NH}_{4}\right)_{2} \mathrm{SO}_{4}$, although in some cases the molecular mass was incorrectly calculated. A sample response from student S3 is presented in Figure 3, where the numerator represents the atomic mass of nitrogen and the denominator the molecular mass of the respective compounds. 


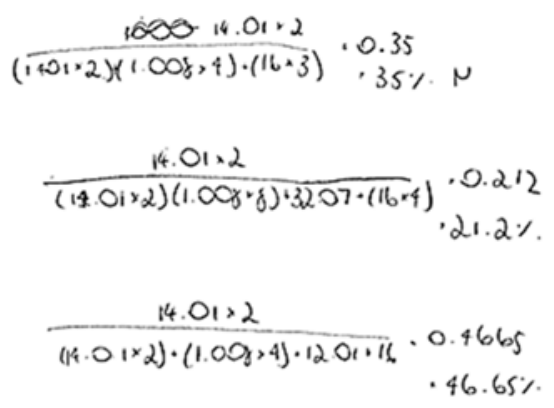

Figure 3. Calculation of percentage composition

Type 3:Relationship between percentage composition, molecular mass and formula. In the two sample tasks in Type 3, we analyzed the solutions presented by the students with regard to the relationship between percentage composition, molecular mass and molecular formula. Our objective was to scrutinize the ways in which they operated with percent in such situations. We present two sample answers for question 3.1, one incorrect (Figure 4(a)) and one correct (Figure 4(b)) to illustrate the procedural and conceptual meaning that the students gave to percent in chemistry tasks. In Figure 4(a), student S6 applied the given percent directly on the atomic masses. Such an error is evidence of inadequate conceptual knowledge of chemistry and is a possible characterization of the operator meaning attribution of percent. In Figure 4(b), student S8 interpreted a percent as a ratio and compared the atomic mass of oxygen and sulfur to observe that two atoms of oxygen are required for the atomic masses to be equal.

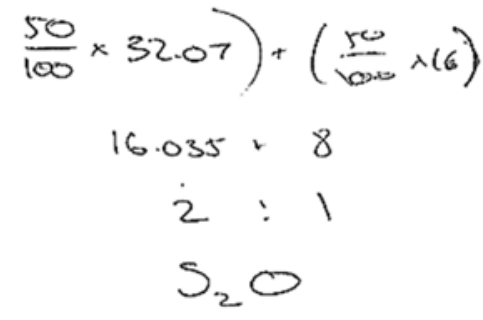

(a)

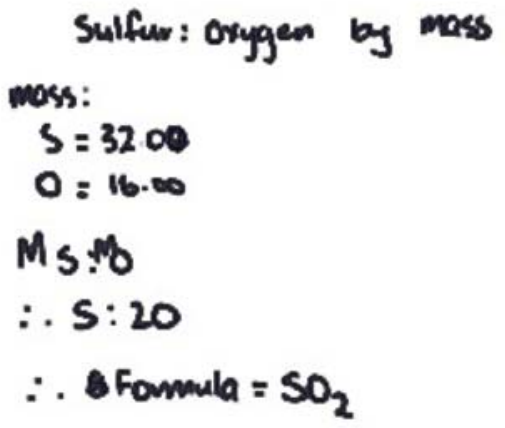

(b)

Figure 4. Interpretation of percent as an (a) operator and (b) ratio

In a variation to the above task, in question 3.2, we gave them the molecular formula $\left(\mathrm{EH}_{3}\right)$ and the percentage composition of one element $(90 \%$ of $\mathrm{E}$ ) in the compound and asked them to find the atomic mass of the unknown element (E). The strategy used by one of the participants (S6) is shown in Figure5. The student translated the given percent $(90 \%)$ in terms of a multiplicative comparison statement ('9 times larger than', see Figure 5) or possibly a ratio, E: $\mathrm{H}=90 \%: 10 \%=9: 1$, although she did not represent it as such. Complementarily, the student deduced that $10 \%$ of hydrogen corresponds (proportionally) to the molecular mass $(3 \times 1.008)$ grams. Such a deduction allowed her to find the atomic mass of $\mathrm{E}$ as $9 \times 3.024=27.216 \mathrm{~g} / \mathrm{mole}$. 


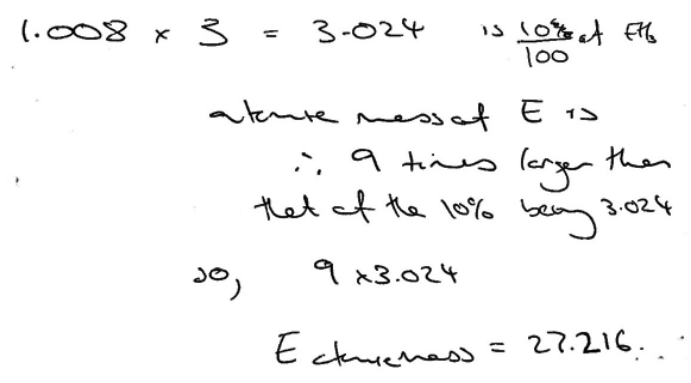

Figure 5. Percent as a multiplicative comparison statement

Type 4:Percent yield. We recall that percent yield refers to the ratio of actual amount of chemical produced to the theoretical amount expected, expressed as a percentage. Questions 4.1 and 4.2 focus on percent yield. We comment on question 4.2 as question 4.1 was generally well answered by the students, with minor slips in using the mole ratio. The solution provided by student $\mathrm{S} 7$ for question 4.2 is presented in Figure 6(a). In the first step, the student determined the amount of glucose that was used $(60 \%$ of $45 \mathrm{~g}=27 \mathrm{~g})$. She then converted the resulting mass $(27 \mathrm{~g})$ into moles (i.e., 0.1498701126$)$ and used the chemical equation to deduce that $2 \times 0.1498701126=0.2997402251$ moles of glucose is produced. Finally, she converted the 0.2997402251 moles of glucose to mass by multiplying by the relative molecular mass: $0.2997402251 \times 46.068=13.808 \mathrm{~g}$.

In contrast, in Figure 6(b), student S2 merely applied the percent directly on the given mass (45g) and did not attend to the molarity consideration. Such a response where the given percent has merely been used as an operator, i.e., a multiplying action performed on a quantity suggests inadequate conceptual knowledge of chemistry. The inadequacy of her chemistry knowledge is further illustrated by the complementarily deduction of the amount of $\mathrm{CO}_{2}$ emitted as $40 \%$.

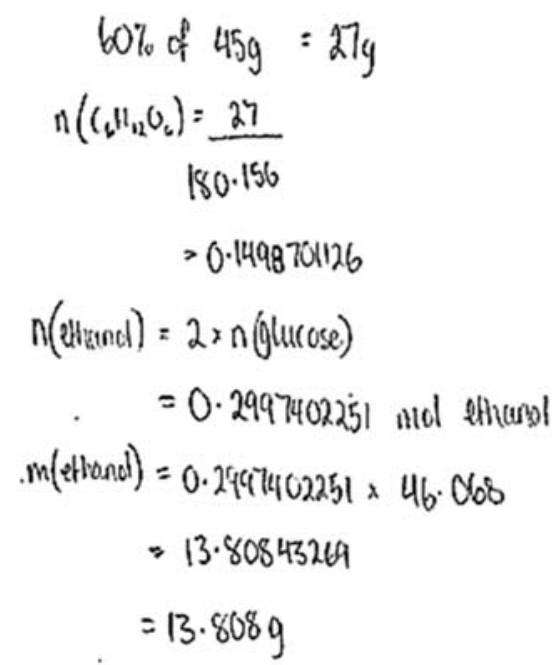

(a)

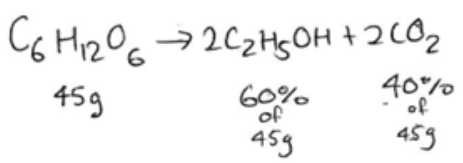

$45 \mathrm{~g} \times 60 \%=27 \mathrm{~g}$

Figure 6. Calculation involving percent yield (a) Correct responseand (b) Incorrect response 
Type 5:Percent purity. Now we provide sample responses to the percentage purity task (question 5.1). We provide two responses to show how students computed the percentage purity differently. In Figure 7(a), student S2reasoned that if all the 15 grams of the sample was $\mathrm{Na}_{2} \mathrm{SO}_{4}$ then the numer of moles of $\mathrm{Na}_{2} \mathrm{SO}_{4}$ would have been 15/142.05 $=0.106$ (where 142.05 is the relative molecular mass of $\mathrm{Na}_{2} \mathrm{SO}_{4}$ ). She then calculated the numer of moles of $\mathrm{BaSO}_{4}$ as $23.3 / 233.37=0.0998$. Since the mole ratio is $1: 1$, then the numer of moles of $\mathrm{BaSO}_{4}$ that should have been produced if the sample was pure is 0.106 . Thus, the fraction of moles that has been produced was used to compute the percentage purity. In Figure $7(b)$, student $\mathrm{S} 7$ computed the number of moles of $\mathrm{BaSO}_{4}$ by dividing the mass produced by the relative molecular mass, i.e., $23.3 / 233.37=0.0998$. Since the mole ratio is $1: 1$, then the numer of moles of $\mathrm{Na}_{2} \mathrm{SO}_{4}$ used is also 0.099 which is converted into mass as $0.099 \times 142.05=14.2 \mathrm{~g}$. Thus, $14.2 \mathrm{~g}$ out of the $15 \mathrm{~g}$ consists of $\mathrm{Na}_{2} \mathrm{SO}_{4}$ and this fration is expressed as a percentage $(14.2 / 15.0) \times 100 \%=$ $94.7 \%$.

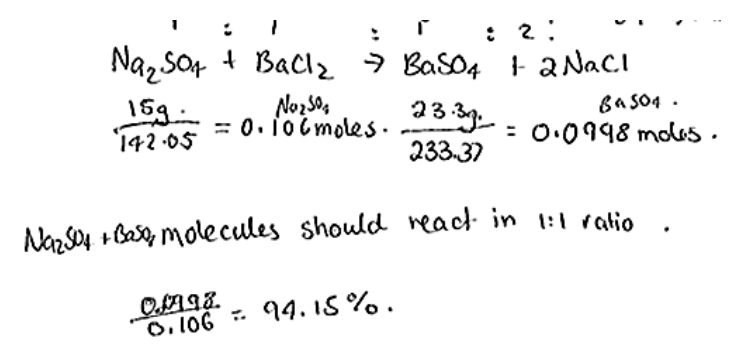

(a)

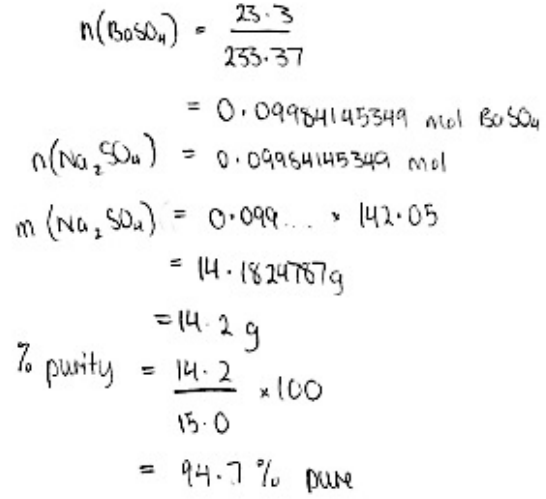

(b)

Figure 7. Calculation involving percentage purity based on (a) moles and (b) mass

Type 6. Concentration expressed in terms of percent. The last type of situations in our categorization involved the use of percent in the definition of concentration. Three problems were included in this category, namely questions 6.1, 6.2 and 6.3. In question 6.1, the students interpreted $20 \%$ (mass/volume) $\mathrm{HCl}$ as "20 gram of $\mathrm{HCl}$ per 100 millilitre" or "200 gram per litre". It appears that student S1 merely converted 20\% to 0.2 to give the following incorrect answer (Figure 8) to conclude that the solution was fairly dilute.

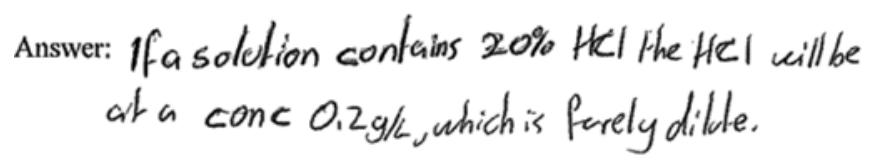

Figure 8. Direct conversion of percent to decimal

In the second question involving concentration (question 6.2), we chose to keep the volume $\left(500 \mathrm{~cm}^{3}\right)$ of the two solutions being mixed constant. Most of the students applied the given percent (i.e., $10 \%$ and $15 \%$ ) directly on the volume as provided by the sample answer (by student S1) in Figure 9(a), rather than using the mass. Such a calculation would be regarded as conceptually accurate if it assumed that the density of the solution is 1 such that the mass is equal to the volume. We cannot assert that the student made this assumption. However, one of the students (S5) did use mass in her calculation (Figure $9(\mathrm{~b})$ )and divided the sum of masses $(5.845 \mathrm{~g}$ and $8.7075 \mathrm{~g}$ ) by 2 since the volume was doubled. 


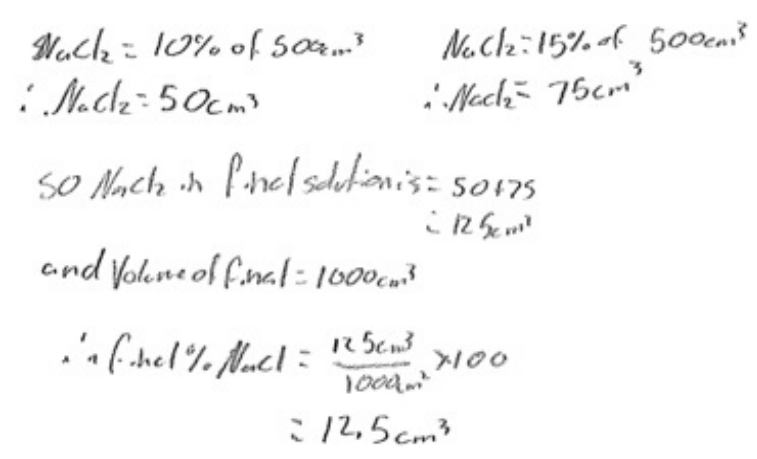

(a)

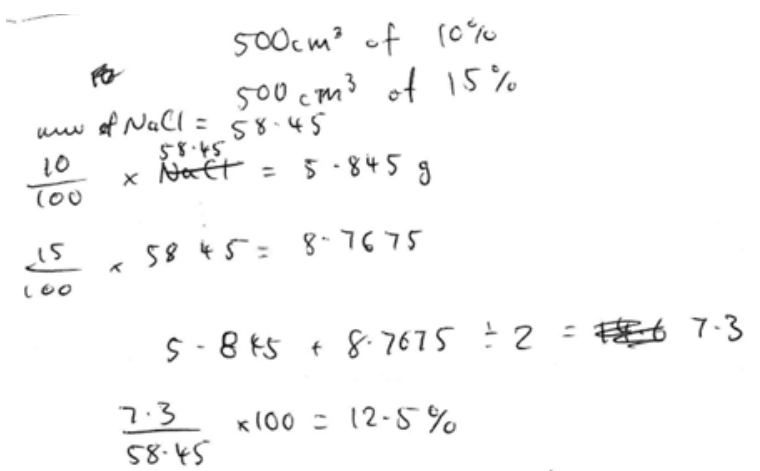

(b)

Figure 9. Calculation of mixed concentration involving (a) volume (b) mass

Question 6.3 was the most demanding problem in this study and the majority of the students could not solve it. It is structurally different from question 6.2. In question 6.2, the concentration of the two solutions to be mixed are given and it is required to find the concentration of the mixed solution. On the other hand, in question 6.3, the concentration of the two individual solutions are provided together with that of the mixed solution and it is required to find the volume of one of the initial solutions. During the data collection, some of the students openly mentioned that it is a difficult problem, uttering: "I am not familiar with boric acid." It is true that boric acid is not a commonly used reagent in first year chemistry classes. However, the difficulty in this problem is not the lack of familiarity with the reagent but the definition of concentration expressed in terms of percent. Here, the referents of the concentrations (6\% and $12 \%)$ of boric acid are concealed in the sense that we do not know the mass per volume. For instance, a solution of boric acid having concentration $6 \%$ can be made from different volumes and masses (by maintaining the fraction mass/volume constant). In other words, when we are dealing with a solution whose concentration is expressed as $6 \%$ boric acid, we cannot explicitly deduce how many grams of boric acid are involved if we do not know the corresponding volume. One has to work with the pair of quantities, mass and volume simultaneously and this is what is referred as an intensive quantity. In the triad, concentration = mass/volume, concentration is inversely proportional to volume. Thus if concentration is doubled, volume is reduced by half.

We comment on two solutions, the first apparently based on a trial solution and the second based on an algebraic approach. In Figure 10(a), it appears that the student (S2) started by the trial solution (1 litre) to get a sense of the problem situation. She ingeniously coordinated the combined volume with the combined concentration. She computed $15 \%$ of $2000 \mathrm{~mL}=300 \mathrm{~mL}$ and $6 \%$ of $1000 \mathrm{~mL}=60 \mathrm{~mL}$ (based on the trial solution that 1 litre or $1000 \mathrm{~mL}$ is used). Thus, the combined volume, 3 litres or $3000 \mathrm{~mL}$ contains $360 \mathrm{~mL}$ of boric acid which is the required concentration, i.e.,12\% ((360/3000) $\times$ $100 \%)$.

In Figure 10(b), student S1 used an algebraic approach by assuming that the volume of the $6 \%$ solution to be added is $\mathrm{v} \mathrm{cm}$. She deduced that $15 \%$ of the two litres amounted to $300 \mathrm{~mL}$ by computing $15 \%$ of 2000 . She conceptualized the combined relation with the $6 \%$ and $15 \%$ solution as evidenced by her equation involving the combined volume of boric acid divided by the total volume. The soundness of this approach lies on the assumption that the density of the solution is one such that mass is equal to volume, although we are not certain that the student made this assumption. 


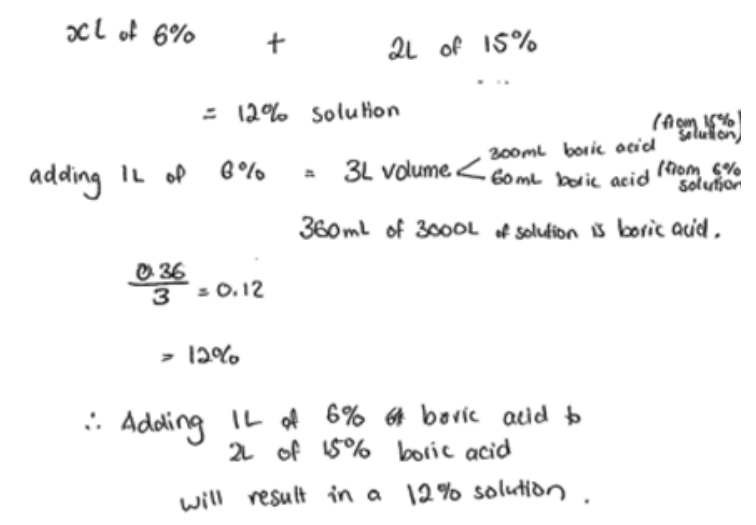

Answer: IL of boric acid.

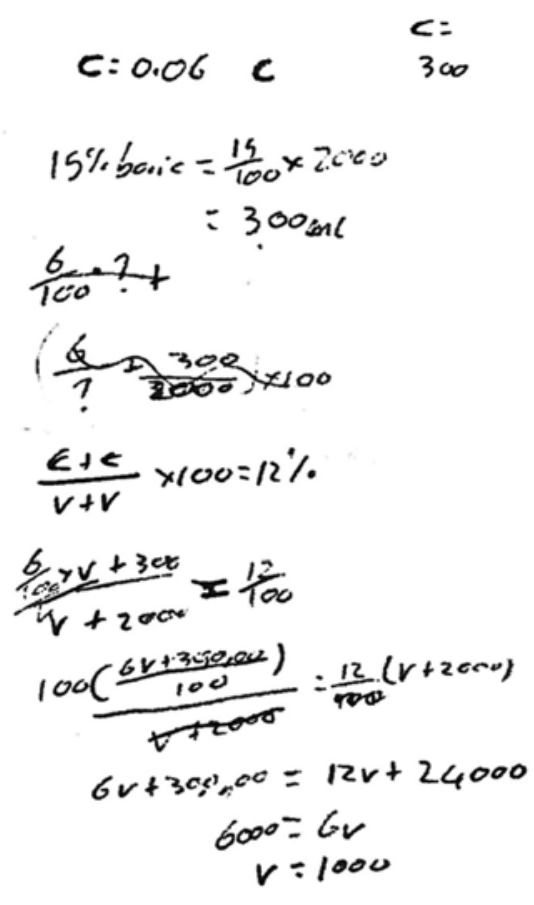

Answer: $1000 \mathrm{ml}=1 \mathrm{c}$

(b)

(a)

(b) S1

\section{Discussion and conclusion}

By examining one mathematical concept (percent) in the acquisition of chemistry knowledge, this study highlights the complexities and subtleties that may be involved in its appropriation. We featured the mathematical structure of percent problems within each of the six categories of situations identified. We focused on the interpretation given by students in solving the percent tasks. We now address the two research questions that guided the study.

The first research question aimed at surveying the use of percent in chemistry with a focus on the ways in which it is used computationally. In this undertaking the knowledge base from the mathematics education literature was particularly useful. Our analysis revealed six types of situations where percent is used in chemistry as summarized in Table 1. Beyond the categorization, we illustrated how percent is functionally used in the description of chemistry concepts. Percent as a number allows the comparison of the relative amount of an element in different compounds. Similarly, percent as a fraction or ratio allows the comparison of the relative amount of different elements in a compound. Of particular importance, is the functional relationship that percent establishes between the molecular mass and molecular formulae. Importantly, the theoretical analysis revealed how percent is used as an intensive quantity. Percent is another mathematical tool for expressing the concentration of a solution. Compared to the definition of concentration in terms of mole per $1000 \mathrm{~cm}^{3}$, a percent expresses concentration in terms of gram per 100 mililitres. By compressing two units (gram per mililitre) into one, percent gets the attribution of an intensive quantity. We concur with Parker and Leinhardt (1995) that the conciseness of the percent language makes its referent implicit.

We now attend to the second research question with regard to the interpretation that the first-year university students attributed to percent. Among the five methods associated with the solution of percent surveyed by the mathematics education literature, three of them were apparent from the strategies used by the students, namely the Unitary Analysis Method (Figure 1(a)), the Proportion 
Method (Figure 1(b)) and the Equation Method (Figure 1(c)). Furthermore, evidence of the fraction, ratio and operator meaning of percent could be observed from the written work of the students. For example, Figure 4(b) illustrates an explicit example of how percent was interpreted as a ratio. Students who had a sound conceptual knowledge of chemistry interpreted percent meaningfully as an operator (e.g., Figure 6(a)) in contrast to those who demonstratedinsufficient knowledge in chemistry (e.g., Figure 4(a) or Figure6(b)). When a percent is interpreted as an operator merely in terms of a multiplying action on a quantity, then the error exhibited in Figure 2 is likely to occur. We hypothesize that the operator meaning of percent (where students have the intuitive tendency of multiplying when they see percent) is one of the causes of students' errors in working with percent. The interpretation that the students gave to the solution containing 20\% (mass/volume) $\mathrm{HCl}$ in question 6.1 provided evidence of their understanding of concentration (expressed as a percentage) in terms of an intensive quantity. However, in question 6.3, concentration is specified only in terms of percent (i.e., neither mass nor volume is given). Thus, here the nature of percent as an intensive quantity imposed an obstacle for the students.

Inadequate conceptual knowledge of chemistry and mathematics. The errors observed in the work of the students are symptomatic of inadequate knowledge of chemistry and mathematics. We posed the context-free numerical percent problem (question 1.2 (c)), knowing the potential difficulties that it generates for middle-school children (Parker and Leinhardt, 1995). Such a difficulty in constructing the base of a percent is still present at the first-year university level. One of the students computed $15 \%$ of 18 instead of finding the number which when multiplied by $15 \%$ gives 18 . Similarly, the conversion of percent to decimal without the consideration of the underlying meaning in Figure 8 reflects the procedural approach that students may use to interpret percent.By the nature of our study, we cannot comment much on the relationship between a student's knowledge of percent in mathematics and its application in chemistry. This is an important question that future research may address with the ground work that has been set in this paper.

In summary, this study makes three contributions. Firstly, it surveys the ways in which percent is used in first-year chemistry to show the type of processing that may be required by students. Secondly, by applying the knowledge base from the mathematics education literature to chemistry, it highlights how the subtleties in the meaning of percent (in terms of a fraction, ratio, operator or intensive quantity) play out in the solution of chemistry problems. Thirdly, it portrays the potential errors or misunderstandings that students may experience in using percent in chemistry.

Limitations of the study.We acknowledge that only a small sample of students was involved in this study. Despite the repeated calls we made to first-year science students, very few responded, leading us to reorient the current study towards a qualitative approach. All of the students that participated had an above average level of performance in mathematics and chemistry as could be inferred from their end-of-secondary school results. We presume that those who responded were fairly confident in their chemistry ability. We wonder how average level students would perform. Furthermore, although we had different types of problems (Table 1), we could not explore a more extended set of questions, given the concentration span necessary to solve the percent problems in a voluntary study. A future study may explore the problems in the instrument on a larger scale. It may also be insightful to conduct a further fine-grained study in relation to students' interpretation of concentration as an intensive quantity in chemistry.However, despite the limitation in the empirical part of the study, the theoretical analysis that we conducted is of significance to chemistry educators.

What are the implications of this study for the teaching and learning of chemistry? The content analysis that we conducted is likely to be beneficial to chemistry teachers. By unfolding the mathematical structure of chemistry problems involving percent, we highlighted their inherent mathematical dimension and complexity. Such an outlook may potentially serve to enlighten chemistry teachers. Both the strategies used by the students (Unitary Analysis Method, Equation Method and Proportion Method) and interpretation they gave (fraction, ratio and operator) to percent, are important knowledge elements from a teaching point of view. Chemistry teachers may not necessarily consider percent problems from these perspectives. In addition, it is important for chemistry teachers to make explicit the practical purposes for which percent is used in the definition of chemistry concepts. Conveying the 
justification for the definition of particular percent concepts (e.g., percentage composition compared to percentage purity) to students can potentially help them to appreciate their relevance rather than merely looking at percent problems as computational exercises. Similarly, the errors observed in this study can be used as illustrative cases to sensitize students about the incorrect interpretations. A significant motivation for making detailed mathematical analysis of chemistry concepts and procedures, and students' strategies, is the insight it provides in terms of the conceptual and computational requirement necessary to make sense of these ideas.

The collaborative endeavour between mathematics and chemistry educators. Research in the areas of mathematics and chemistry education have been conducted rather separately. Although the two subjects are taught as distinct disciplines in the school curricula, as a service subject mathematics intersects quite a significant portion of the chemistry curriculum. Research in mathematics education has generated considerable understanding and developed much theoretical insights in terms of how mathematical ideas in different domains (such as numbers, measurement, algebra and geometry) are developed and the obstacles that may come along the way in the process of acquiring these concepts. Such a knowledge base from the mathematics education literature can productively be used in understanding the challenges that students experience in dealing with the application of mathematics in chemistry problems. Some steps have already been taken (e.g., Ramful and Narod, 2014) with the collaborative work of mathematics and science educators. While the science educator is more inclined to look at the 'science' dimension of the problem, the mathematics educator views the problem from a mathematical perspective. Such collaborative and synergistic endeavours between mathematics and chemistry education researchers can offer insightful understanding of the knowledge that may be required to solve mathematically-oriented, quantitative problems in chemistry and develop instructional strategies to address well-established issues in the application of mathematical concepts in solving chemistry problems.

\section{References}

Blackman A., Bottle S.E., Schmid S., Mocerino M., and Wille U., (2006).Chemistry. Australia: John Wiley \& Sons.

Brown T.L., LeMay Jr H. E., Bursten B. E., Murphy C. J. and Woodward P.M., (2012).Chemistry: the central science, 12th edn. Boston: Prentice Hall.

Coll R., Ali S., Bonato J., and Rohindra D., (2006). Investigating First-Year Chemistry Learning Difficulties in the South Pacific: A Case Study from Fiji.International Journal of Science and Mathematics Education, 4(3), 365-390.

Chang R., (2007).Chemistry, 9th edn. New York: McGraw-Hill.

Chua S. (ed.), (2000).GCE O level Pure Chemistry (Topical)-Worked Solutions. Singapore: Redspot Publishing.

DePierro E., Garafalo F., and Toomey R., (2008). Helping students make sense of logarithms and logarithmic relationships. Journal of Chemical Education, 85(9), 226-1228.

Dole S., Cooper T. J., Baturo A. R., and Conoplia Z., (1997). Year 8, 9 and 10 students' understanding and access of percent knowledge. Proceedings of the 20th. Annual Conference of the Mathematics Education Research Group of Australasia,147-154.

Ebbing D.D., and Gammon S.D., (2005).General Chemistry,8th edn. New York: Houghton Mifflin Company.

Gorin G., (1994).Mole and chemical amount: a discussion of the fundamental measurements of chemistry. Journal of Chemical Education, 71(2), 114-116.

Hoban R., (2011).Mathematical transfer by Chemistry undergraduate students, PhD doctoral dissertation, Dublin City University, Dublin.

Jones L., and Atkins P., (2000).Chemistry -Molecules, matter and change,4th edn, New York: W.H. Freeman and Company.

Kotz J.C., Treichel P.M., and Weaver, G.C., (2006).Chemistry \& chemical reactivity,6th edn. Australia: Brooks/ColeThompson.

Lembke L.O. (1991). The development of concepts and strategies used in solving percent problems, PhD doctoral dissertation, University of Missouri, Columbia.

Leopold D. G., and Edgar B., (2008). Degree of mathematics fluency and success in second-semester introductory chemistry.Journal of Chemical Education, 85(5), 724-731.

Nesher P., (1988). Multiplicative school word problems: theoretical approaches and empirical findings, in J. Hiebert and M. Behr (Ed.), Number concepts and operations in the middle grades (pp. 19-40).Reston: Lawrence Erlbaum Associates and National Council of Teachers of Mathematics. 
Park E.J., and Choi K., (2012). Analysis of student understanding of science concepts including mathematical representations: Ph values and the relative differences of Ph values.International Journal of Science and Mathematics Education, 11, 683-706.

Parker M., and Leinhardt G., (1995). Percent: A privileged proportion.Review of Educational Research, 65, 421-482.

Pienta N. J., (2003). A placement examination and mathematics tutorial for general chemistry.Journal of Chemical Education, 80(11), 1244-1246.

Potgieter M., Harding A., and Engelbrecht J., (2008). Transfer of algebraic and graphical thinking between mathematics and chemistry.Journal of Research in Science Teaching, 45(2), 197-218.

Quinn T. J.,and Mills I. M., (1998).The use and abuse of the terms percent, parts per million and parts in 10 $0^{\mathrm{n}}$. Metrologia,35, 807-810.

Ramful A., and Narod, F., (2014). Proportional reasoning in the learning of chemistry: levels of complexity.Mathematics Education Research Journal, 26, 25-46.

Risacher B. F., (1992).Knowledge growth of percent during the middle school years, PhD doctoral dissertation, University of Delaware, Delaware.

Scott F. J., (2012). Is mathematics to blame? An investigation into high school students' difficulty in performing calculations in chemistry.Chemistry Education Research and Practice, 13(3), 330-336, DOI: 10.1039/C2RP00001F.

Siemon D., Beswick K., Brady K., Clark J., Faragher R. and Warren, E., (2011).Teaching mathematics - Foundations to middle years. Australia: Oxford University Press.

Silberberg M.S., (2009). Chemistry -The molecular nature of matter and change, 5th edn. Boston: McGraw Hill.

Singer J. A., Kohn A. M. and Resnick L.B., (1997). Knowing about proportions in different contexts, in Nunes, T. and Bryant, P. (ed.), Learning and teaching Mathematics: an international perspective, Sussex: Psychology Press, pp. 115132.

Spencer H., E., (1996). Mathematical SAT test scores and college chemistry grades.Journal of Chemical Education, 73(12), 1150-1153.

Van Lanen R. J, Lockie, N.M. and McGannon T., (2000). Predictors of nursing students' performance in a one-semester organic and biochemistry course.Journal of Chemical Education, 77(6), 767-770. 


\section{Appendix}

Question 1.1. Information is given below about the nitrogen content of four different fertilizers. Use this diagram to answer the following questions. (i)Which of the fertilizers $\mathrm{W}, \mathrm{X}, \mathrm{Y}$, or $\mathrm{Z}$ would you use for a crop that needs a high content of nitrogen? (ii)How many grams of nitrogen are supplied if 500 grams of fertilizer $Z$ is spread over the ground? (modified from Coll et al., 2006).

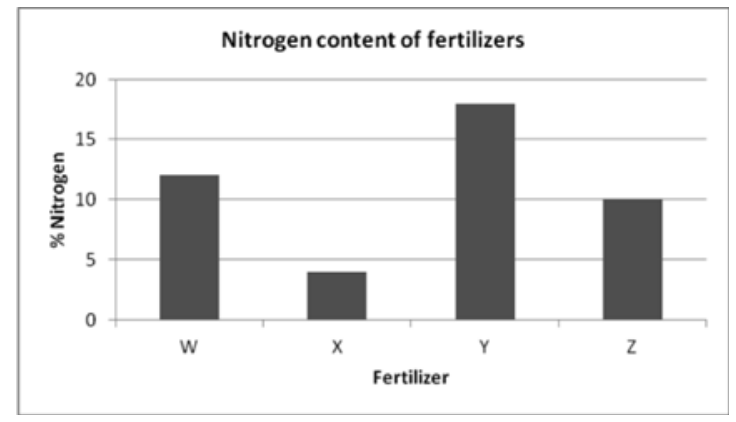

Question 1.2: Fill in the missing number:
(a) $8=$ $\%$ of 32;
(b) $15=$ $\%$ of 10 ; (c) $15 \%$ of $=18$.

Question 1.3: A hydrocarbon contains $75 \%$ by mass of carbon. What does that mean?

Question 1.4: The equation for the combustion of methane $\left(\mathrm{CH}_{4}\right)$ is as follows:

$$
\mathrm{CH}_{4}+2 \mathrm{O}_{2} \rightarrow \mathrm{CO}_{2}+2 \mathrm{H}_{2} \mathrm{O} \text {. }
$$

$6000 \mathrm{~cm}^{3}$ of oxygen is needed to burn $2 \mathrm{~g}$ of methane. Air contains $21 \%$ of oxygen. What volume of air is needed to burn $2 \mathrm{~g}$ of methane? (modified from Chua, 2000).

Question 2.1: Ammonium nitrate $\left(\mathrm{NH}_{4} \mathrm{NO}_{3}\right)$, ammonium sulfate $\left(\mathrm{NH}_{4}\right)_{2} \mathrm{SO}_{4}$, and urea $\left(\mathrm{NH}_{2}\right)_{2} \mathrm{CO}$, are all fertilizers that contains nitrogen. A shop sells ammonium nitrate, ammonium sulfate and urea in 1kilogram bags. Which bag contains the most nitrogen by mass? Justify your answer (modified from Chua, 2000).

Question 3.1: A compound X contains $50 \%$ sulphur and $50 \%$ oxygen by mass. What is the empirical formula of compound X? (modified from Chua, 2000)

Question 3.2: An element $\mathrm{E}$ forms a hydride $\mathrm{EH}_{3}$ which contains $90 \%$ of $\mathrm{E}$, by mass. What is the relative atomic mass of $\mathrm{E}$ ? (modified from Chua, 2000)

Question 4.1:Propan-2-ol is manufactured by the reaction between steam and propene as shown by the following equation, $\mathrm{H}_{2} \mathrm{O}+\mathrm{C}_{3} \mathrm{H}_{6} \rightarrow \mathrm{C}_{3} \mathrm{H}_{8}$. From $200 \mathrm{~kg}$ of propene, the manufacturer obtained $150 \mathrm{~kg}$ of propan-2-ol. Calculate the percentage yield (modified from Chua, 2000).

Question 4.2: Ethanol is produced from glucose according to the following equation: $\mathrm{C}_{6} \mathrm{H}_{12} \mathrm{O}_{6} \rightarrow 2 \mathrm{C}_{2} \mathrm{H}_{5} \mathrm{OH}+2 \mathrm{CO}_{2}$. What is the mass of ethanol that could be obtained from $45 \mathrm{~g}$ of glucose, assuming only $60 \%$ conversion of glucose into ethanol? (modified from Chua, 2000)

Question 5.1: When sodium sulfate and barium chloride solutions are mixed, the following reaction takes place: $\mathrm{Na}_{2} \mathrm{SO}_{4}+\mathrm{BaCl}_{2} \rightarrow \mathrm{BaSO}_{4}+2 \mathrm{NaCl}$. $15.0 \mathrm{~g}$ of an impure sample of sodium sulfate was added to excess barium chloride solution. The mass of barium sulfate was found to be $23.3 \mathrm{~g}$. Calculate the percentage purity of the sample.

Question 6.1:What does a solution containing 20\% (mass/volume) $\mathrm{HCl}$ means to you? 
Question 6.2: $500 \mathrm{~cm}^{3}$ of a solution containing $10 \%$ by mass of sodium chloride is mixed with $500 \mathrm{~cm}^{3}$ of a solution containing $15 \%$ by mass of sodium chloride, what is total percentage of sodium chloride in the mixture?

Question 6.3:A solution containing 6\% boric acid is to be mixed with 2 litres of a solution which is $15 \%$ boric acid in order to obtain a solution which is $12 \%$ boric acid. How much of the $6 \%$ solution must be used? (Nicoll and Francisco, 2001). 